\title{
Exploring marriage-parenting typologies and their contextual antecedents and developmental sequelae
}

\author{
JAY BELSKY $^{a}$ AND R. M. PASCO FEARON ${ }^{b}$ \\ ${ }^{a}$ Birkbeck University of London; and ${ }^{b}$ University College London
}

\begin{abstract}
To identify types of families, latent-class analysis was applied to (reported) marriage and (observed) parenting measures obtained during the infancy, toddler, and/or preschool years for 828 two-parent families participating in the NICHD Study of Child Care. Five types of families were identified: Consistently Supportive (i.e., good parenting, good marriage, $15 \%$ of sample), Consistently Moderate (i.e., moderate marriage, moderate parenting, 43\%), Consistently Risky (i.e., poor parenting, poor marriage, 16\%), Good Parenting/Poor Marriage (19\%), and Poor Parenting/Good Marriage (7\%). When groups were compared in terms of contextual antecedents (measured at child age 1 month) and child cognitive-academic and socioemotional functioning in first grade, results indicated (a) that contextual risks increased linearly and children's functioning decreased linearly as one moved across the first three aforementioned groups; and after controlling for group differences in background factors (b) that children in the Good-Parenting/Poor-Marriage families outperformed those in the Poor Parenting/Good Marriage; (c) that there was evidence of "added value" developmentally when children experienced two sources of support (i.e., good marriage and good parenting) rather than just one (i.e., good marriage or good parenting); but (d) that there was only modest evidence of protective buffering whereby children experiencing just good parenting (but not just good marriages) outperformed children experiencing poor parenting and poor marriages. Results are discussed in terms of the relative influence of marriage and parenting on child development and the potential benefits of applying typological approaches to the study of marriage-parenting family subsystems.
\end{abstract}

For many years up until the late 1970s and early 1980 s, investigation of marriage, parenting, and child development was spread across a variety of disciplines and subfields (Aldous, 1977; Belsky, 1981). Family sociologists interested in how marriages change across the family life cycle charted the ups and downs of marital conflict and communication, in mostly cross-sectional studies, as families moved from the couple stage, to that of bearing firstborns,

The research described herein was supported by a cooperative agreement with the National Institute of Child Health and Human Development (U10-HD25420). The authors express their appreciation to all collaborating investigators of the NICHD Study of Early Child Care.

Address correspondence and reprint requests to: Jay Belsky, Institute for the Study of Children, Families, and Social Issues, Birkbeck University of London, Malet Street, London WC1E 7HX, UK; E-mail: j.belsky@bbk.ac.uk. to that of raising young children and adolescents, to the period of the empty nest when children had moved away from their family of origin (Anderson, Russell, \& Schumm, 1983; Burr, 1970; Duvall, 1971). Clinical psychologists, in contrast, investigated linkages between problematic child functioning and marital quality, repeatedly finding that distressed marriages and problematic child behavior often went together (Buehler, Anthony, Krishnakumar, Stone, Gerard, \& Pemberton, 1997; Depner, Leino, \& Chun, 1991; Emery, 1982; Reid \& Crisafulli, 1990). In the case of developmental psychology, the marital relationship was conceptualized as a potential source of influence on parenting, so it was not normative changes in marriage nor distressed marriages that were the principal focus of inquiry, but rather the interrelation of marriage and parent- 
ing at the level of of individual differences (e.g., Belsky, 1981, 1984; Feldman, Nash, \& Aschenbrenner, 1983; Goldberg \& Easterbrooks, 1984; Pedersen, Anderson, \& Cain, 1980).

Eventually, these lines of inquiry converged to foster the multidisciplinary investigation of the developing family system, that is, the interrelation of marriage, parenting, and child development (Belsky, Rovine, \& Fish, 1989; Grych, 2002). What began as a slow trickle of investigation focused mostly on the infant years (Belsky, Youngblade, Rovine, \& Volling, 1991; Cowan \& Cowan, 1992; Cox, Owen, Lewis, \& Henderson, 1989), clearly revealing positive associations between marriage and parenting and sometimes suggesting that the linkage was stronger in the case of fathers (e.g., Cowan \& Cowan, 1992; Cox et al., 1989; Goldberg \& Easterbrooks, 1984), perhaps because fathering was a less socially scripted role and thus more susceptible to influence than mothering (Belsky, 1979; Belsky et al., 1991), became almost a torrent (e.g., Buehler \& Gerard, 2002; Brody, Pellegrini, \& Siegel, 1986; Jouriles, Murphy, Farris, Smith, Richters, \& Waters, 1991; Lindahl \& Malik, 1999; for reviews, see Belsky \& Jaffee, in press; Grych, 2002). Indeed, by the turn of the last century, there was enough work to generate two meta-analyses which showed, in the main, that well functioning marriages and skilled parenting went together (Erel \& Burman, 1995; Krishnakumar \& Buehler, 2000); and this was so across the infant, preschool, middle-childhood, and adolescent years (see Belsky \& Jaffee, in press).

Clinicians and developmentalists alike came to appreciate the fact that simply discovering (and repeatedly demonstrating) that problematic marriages and troubled child behavior often went together was not the same as understanding the processes which accounted for this family-system phenomenon (Howes, Cicchetti, $\&$ Rogosch, 2000). Thus, one line of inquiry pursued in the 1980s and through the 1990s explored the proposition that the apparent effect of marital conflict on problematic child behavior is mediated by parenting (e.g., Cox, Paley, \& Harter, 2001; Fincham, Grych, \& Osburne, 1994; Harold \& Conger, 1997). Also, repeat- edly, evidence emerged consistent with this proposition, indicating that when marriages are in distress, sensitive, responsive, and skilled parenting is often undermined, leading, apparently, to child behavior problems (Buehler \& Gerard, 2002; Fauber, Forehand, Thomas, \& Wierson, 1990; Harold, Fincham, Osburne, \& Conger, 1997; Osborne \& Fincham, 1996).

Questions about the interrelation of marriage, parenting, and child development also led investigators to focus upon coparenting (Belsky, Crnic, \& Gable, 1995; Belsky, Putnam, \& Crnic, 1996; Floyd, Gilliom, \& Costigan, 1998; McHale, 1995), defined as the family-systems' process by which parents work together as a cooperative, harmonious unit (or fail to) when it comes to raising their children (Ahrons, 1981; for review, see Buchanan \& Waizenhofer, 2001). Central to this work was the presumption that scholars needed to distinguish between marital processes that did and did not directly involve parenting and/or the child, given the supposition that child-related marital processes would exert a stronger influence on the developing child than more general marital processes. Jouriles and associates (1991) reported evidence consistent with such theorizing and related work showed that (observed) coparenting predicted children's development (for review, see McHale, Khazan, Erera, Rotman, DeCourcey, \& McConnell, 2002), even after taking into account parenting processes (Belsky et al., 1996; McHale \& Rasmussen, 1998; Stright \& Neitzel, 2003). Stright and Neitzel (2003) found, moreover, that supportive coparenting functioned as a protective factor, reducing to insignificance the anticipated adverse impact of rejecting parenting.

Additional theory and research was based on the proposition that marital relations, especially processes involving the dynamic nature and resolution of marital conflict, could directly affect child development (i.e., need not be mediated by parenting), especially the child's emotional arousal (for review, see Cummings \& Davies, 1994, 2002). Indeed, Davies and Cummings' (1994; Davies \& Forman, 2002) emotional-security hypothesis stipulated, essentially, that children's sense of security is not exclusively rooted in their interactions with 
their parents, as often assumed from the perspective of traditional attachment theory. Growing up in a household in which parents have a harmonious loving relationship should directly foster emotional security in the child, whereas being raised in one in which parents are constantly squabbling or refusing to communicate with one another should instead promote insecurity, especially if conflicts remain unresolved.

Consideration of the indisputable progress that has been made over the past two decades in studying marriage, parenting, and child development illuminates how much the field has moved away from some of its familysystem roots. Most notably, whereas much early writing about family systems focused upon different types of families, for example, the enmeshed family in which psychological boundaries between parents and children prove porous and children can end up reversing roles and being caretakers of parents (Minuchin, 1974), most of the research conducted by family sociologists, clinical psychologists, and developmentalists in recent years has conceptualized, and measured, family processes in continuous rather than categorical terms (but see, for exception, Belsky, Woodworth, \& Crnic, 1996a, 1996b; Johnson, 2003; O'Connor, Hetherington, \& Reiss, 1998). Thus, rather than distinguishing types of families in which marital and parenting processes operate differently (e.g., enmeshed, disconnected, integrated), linear variation in marital quality is repeatedly associated with linear variation in parenting, yielding a result showing that, in general, marital quality is positively associated with growth-promoting parenting (Belsky, 1981; Belsky \& Jaffee, in press; Erel \& Burman, 1995). The evidence thus seems to indicate that children thrive when they grow up in households in which couples are happy and communicate well, in part because wellfunctioning marriages promote sensitive, supportive, and authoritative (as opposed to authoritarian) parenting, whereas the opposite tends to be the case when marriages are distressed or highly conflicted.

Reflection upon such findings, especially in light of the original typological thinking of family-systems' scholars (e.g., Haley, 1976;
Minuchin, 1974; Walsh, 1993), raises the possibility that the broad conclusions just drawn about the interrelation of marriage, parenting, and child development might mask as much as they illuminate (Howes et al., 2000; O'Connor et al., 1998). This is because it might well be the case that the reason why marital quality and parenting tend to be only modestly positively associated or that the relation between marital distress and child dysfunction is far from perfect is because there are different types of families in which marital quality, parenting, and child development go together in rather different ways. Whereas in some households poor marriages and inept parenting might co-occur, for example, in others this might not be so. Were this the case, as it proved to be in Johnson's (2003) research on whole-family functioning and child development during the early school years and in O'Connor et al.'s (1998) study of family systems and adolescent development, such variation in the marriage-parenting relation would go undetected in many standard correlational and regression analyses designed to illuminate associations between marriage, parenting, and child development. This is because these investigatory approaches essentially assume a basic dose-response relation between predictor and outcome.

Even though many standard analytic strategies assume such linear dose-response relations, theory often does not. Indeed, a systems' view of families cautions against embracing "the prevailing model of family influences that focuses on the specific, independent influences of relationships and assumes that identical processes exist in all families" (O'Conner et al., 1998, p. 354; emphasis in original). Rather than anticipating direct connections between, for example, marital processes and child well-being, a systems' perspective emphasizes the compensatory or exacerbating role of parent-child relations. So, too, of course, does the developmental psychopathological perspective (Cicchetti \& Cohen, 1995) and contemporary thinking about the determinants of parenting (Belsky, 1984), each of which embraces the central notion that risk and protective factors can, respectively, amplify or attenuate anticipated associations between predictors and outcomes. 
In point of fact, most social and behavioral scientists who study children and families today would not expect anything close to a perfect 1:1 relation between marital conflict and problematic parenting because it is well appreciated that other factors and processes can moderate even such theoretically expected relations. It is certainly possible, then, that parenting can remain skilful even in the face of a highly conflicted marriage or that a good marriage and problematic parenting can go together. Suggestive evidence that this is indeed the case can even be found in some studies using basic correlational/regression approaches. Even though it remains the case that, in the main, the spillover hypothesis would seem to account for many of the findings in the literature, as good or poor marital functioning is related, respectively, to more or less growth-promoting parenting, some evidence has been reported consistent with the compensatory hypothesis. That is, a not insubstantial number of studies find a negative rather than positive association between measures of marital quality and parenting (e.g., Amato, 1986; Burman, John, \& Margolin, 1987; Dickie, 1987; Grossman, Pollack, \& Golding, 1988; Stoneman, Brody, \& Burke, 1989). Such data suggest that the common assumption that all good (or bad) things go together (e.g., happy marriages, skilled parenting) may be incorrect, as poor marital quality and seemingly positive parenting have been found to co-occur in a number of investigations. Perhaps more compelling evidence to this effect comes from O'Connor et al.'s (1998) aforementioned investigation, which identified different types of families, some in which high levels of supportive parenting and high-quality marital relations co-occurred, and others in which this was decidedly not the case (see also Johnson, 2003).

Appreciation of the fact that associations between marital and parenting quality may be more variable than often assumed led us to adopt a typological approach to studying marriage, parenting, and child development in the current inquiry. Drawing upon a sizeable data archive assembled by the NICHD Early Child Care Research Network $(1999,2000,2003)$ as part of its ongoing study of the short- and longer term effects of early child care experience, which is not at all a focus of this investigation, we sought to identify different types of twoparent households by subjecting to latentclass analysis data collected on marriage and parenting. Typological analysis has been employed successfully by ourselves (Belsky et al., 1996a, 1996b) and others (Johnson, 2003; Mandara \& Murray, 2002; O'Connor et al., 1998) guided by family-systems' thinking in attempt to identify meaningful subgroups of families. The marriage data used in the latentclass analysis emanates from repeatedly collected spousal reports of intimacy in the partner relationship and from (in some cases) repeated measurements of observed mothering and fathering made between the time the child was 6 and 54 months of age; in all cases, repeated measurements of the same construct over time are averaged together to reduce the loss of cases due to missing data and to increase measurement reliability. After identifying what were judged to be meaningful types of families, which was based on marriage and parenting data alone, we examined the contextual antecedents of the identified family types, drawing upon family demographic and background information obtained when families were first enrolled in the NICHD Study (i.e., children were 1 month old). We selected from a long list of possibilities ones that previous analyses had revealed to be related to family processes or might be expected to. Ultimately, our goal was to determine how family subgroups differed from one another on these contextual antecedents so such preexisting differences could be taken into account when examining child "outcomes."

Thus, our final set of analyses examined a host of social-behavioral and cognitive measurements obtained from teachers and via standardized cognitive assessment when children were in first grade in hopes of illuminating the developmental sequelae of growing up in different types of families. Although virtually all the developmental outcomes mentioned in the preceding summary of research on marriage, parenting, and child development have been socioemotional in nature, indeed principally concerned with problem behavior (e.g., Johnson, 2003), in this investigation we adopted a broader perspective on child functioning. 
Because we conceptualized this research as exploratory in some respects and as focused upon a nonclinical sample of children and families, it seemed reasonable to draw broadly from the child measurements included in the NICHD Study of Child Care in this effort to apply family systems-oriented typological thinking to the study of interrelation of marriage, parenting, and child development. At times in the course of scientific investigation it is quite appropriate to focus narrowly on particular developmental outcomes, especially when highly specified predictions derive from strong theory. At other times, however, casting a net too narrowly may lead investigators to miss what might otherwise be detected. This seemed possible in the current investigation because in previous research using the NICHD study data set, we have discovered that early attachment security predicts later cognitive-linguistic development (Belsky \& Fearon, 2002a, 2002b), something difficult to explain within the confines of traditional attachment theory (Sroufe, 1988; but see Meins, 1997), even though the same result has emerged in other investigations (van Ijzendoorn, Dijkstra, \& Bus, 1995). Thus, when it came to asking questions about types of families based on the configuration of marriage and parenting processes, we chose to consider not only socioemotional development, but cognitive-linguistic functioning as well.

Despite casting our net rather broadly with respect to developmental outcomes, we appreciated the scientific risks involved in deploying an exploratory approach. Thus, when it came to illuminating the potential effects of marriage and parenting on child development, rather than comparing each and every identified family type with each and every other type of family identified in the latent-class analysis, we chose to carry out more selective comparisons to answer more targeted questions that emerged from consideration of the types of families identified. For example, upon identifying one type of family that scored consistently high across mother and father marriage and parenting measures and another type in which (relatively) high levels of parenting coincided with (relatively) low levels of marital quality (for both parents), we asked whether good marital functioning "added value," devel- opmentally, to good parenting by comparing the functioning in first grade of children from these two groups. Because some readers might be interested in making comparisons beyond those presented in this report, we have included in the tables presented information that could be used to compare any of the identified groups with any other identified groups. The interested reader should also be aware that all data used in this report is in the public domain and can be obtained by any qualified researcher for scientific purposes (see Applying for Data at http://secc.rti.org/).

\section{Methods}

\section{Participants}

Participants were recruited from 31 hospitals located in or near Little Rock, AR; Irvine, CA; Lawrence, KS; Boston; Philadelphia, PA; Pittsburgh, PA; Charlottesville, VA; Morganton, NC; Seattle, WA; and Madison, WI. During selected 24-hr sampling periods in 1991, 8,986 women giving birth were visited in the hospital. Of these, 5,416 met the eligibility criteria for the study and agreed to be contacted after their return home from the hospital. A subset of this group was selected in accordance with a conditional-random sampling plan that was designed to ensure that recruited families reflected the demographic diversity (economic, educational, and ethnic) of the catchment area at each site. When the infants were 1 month old, 1,364 families (58\% of those contacted) with healthy newborns were enrolled in the study.

Of the 1,364 families who took part in the NICHD Study of Early Child Care, only a subset is are included in this report, namely those in which two parents lived with the child throughout the 1-54 month age period (so that marriage could be assessed), fathers participated in the research process, and for whom first-grade child outcome data were available. This subset totaled, at its maximum, 829. To be noted is that only 6 of the 10 research sites gathered data from fathers through 24 months postpartum (because of concerns about attrition), but thereafter fathers were studied in all sites. To maximize the analysis sample, father (and mother) data on marriage and parenting 
were averaged across the multiple measurement occasions in which parents participated.

Attrition analyses revealed significant differences between the 829 two-parent families who are the focus of this report and the other 374 families with two parents at the time of enrolment into the NICHD Study of Early Child Care when infants were 1 month of age but for whom no first-grade child outcomes were available or for whom no data from fathers (i.e., fathering, marital quality) were available (because fathers refused to participate). A logistic regression predicting group membership (those two parent families included in the current report versus those not included) from a set of background variables (described below) was highly significant, $\chi^{2}$ $(9)=38.6, p<.001$. Looking at the independent predictors in this analysis, the results indicated that, relative to two-parent families not included in this report, two-parent families included in this report had a significantly higher maternal age (current sample mean $=29.18$, $S D=5.39$; excluded sample mean $=27.77$, $S D=5.31$; odds ratio $=1.05, p=.004)$, more progressive attitudes to child rearing (current sample mean $=33.10, S D=3.37$; excluded sample mean $=32.32, S D=3.44$; odds ratio $=$ $1.05, p=.023)$ and were more likely to be White (current sample 88.9\%; excluded sample $78.9 \%$; odds ratio $=1.47, p=.034$ ). There were no independent differences between these two subsets of families on child birth order, planned pregnancy, income to needs ratio, paternal occupation, maternal depression, or maternal reported social support. In light of these results, it should be evident that the substantive analyses reported herein pertaining to types of families and their developmental antecedents and sequelae underrepresent minority families, families with younger mothers, and families with more authoritarian (i.e., less progressive) maternal childrearing attitudes. The likely effect of these sampling biases are unknown but should be kept in mind when considering results to be reported.

\section{Procedures and measures}

Data for this report pertaining to marriage and parenting were collected on one or more occa- sions between 6 and 54 months postpartum. Data on family background factors that are conceptualized for purposes of this investigation as developmental antecedents of family types were obtained when families were enrolled in the study at 1 month postpartum. Finally, child-outcome data were gathered when children were in first grade. Each set of data is described in turn.

Marriage and parenting: 6-54 months. The quality of mother's and father's marriage was assessed using the six-item Intimacy subscale of the Personal Assessment of Intimacy in Relationships Inventory (PAIR; Schaefer \& Olson, 1981), which was administered to participating mothers and fathers when children were 1 , $6,14,24,36$, and 54 months of age. Items are rated using seven-point scales. An example of an item is "My spouse/partner can really understand my hurts and joys." A scale score was created by calculating the mean of the six items, after reflecting the appropriate items. A higher score indicates greater intimacy. The subscale scores had high internal consistency (in excess of .8) at all times of measurement and were standardized and summed for each parent to create average marital quality scores.

Mother's parenting was measured by means of a composite index of maternal sensitivity (see below), based upon evaluations of observed maternal behavior at $6,15,24,36$, and 54 months (NICHD Early Child Care Research Network, 1999, 2003). Mother-child interaction was videotaped in semistructured 15-min observations at each age. The observation task at 6 months had two components. In the first $7 \mathrm{~min}$, mothers were asked to play using any toy or object available in the home or none at all; for the remaining $8 \mathrm{~min}$ mothers were given a standard set of toys they could use in play with their infants. At 15, 24, and 36 months, the observation procedures followed a threebox task in which mothers were asked to show their children age-appropriate toys in three containers in a set order (see Vandell, 1979). Thus, at 36 months, for example, a set of washable markers, stencils, and paper was in the first container, a set of dressup clothes and a toy cash register in the second, and a set of Duplo blocks with a picture of a model in the third 
container. At 54 months, interaction activities included two tasks that were too difficult for the child to carry out independently and required the parent's instruction and assistance. In addition, a third activity was included that encouraged play between mother and child. The first activity was completing a maze using an Etch-A-Sketch that had been altered by attaching a maze to the screen. The second activity was to form a series of same-sized rectangular cube "towers" from variously shaped wooden blocks. The third activity was play with a set of six hand puppets, consisting of two parrots, two frogs, and two blue alligators.

Father's parenting was measured by means of a composite index of paternal sensitivity (see below), based upon evaluations of observed paternal behavior during 15-min videotaped observations of father-child play at 6, 36, and 54 months (NICHD Early Child Care Research Network, 2000). Procedures used with fathers were very similar to those used with mothers at corresponding ages. Recall that these fathering data were gathered at only 6 of the 10 research sites at when children were 6 and 36 months, but at all sites at 54 months.

Data were collected across sites by research assistants who attended a common training meeting prior to the data collections at each age of measurement. To ensure standard data collection procedures across the sites, each data collector first passed certification procedures based on a central certifier's review and approval of videotaped administrations of the procedures.

The videotapes of mother- and fatherchild interaction were shipped to a central, nondata collection location for coding. Coders were blind to other information about the families. Teams of five or six coders scored the videotapes from each time period, with some overlapping membership in the teams across the different ages (i.e., one coder served on all three of the teams, two served on two of the teams). Coders received intensive training and supervision and met periodically to recode tapes together as a group throughout the period of formal scoring.

At 6, 15, and 24 months, the parental sensitivity composite was constructed based on three four-point ratings: sensitivity to nondistress, positive regard, and intrusiveness (reversed). In the case of 36- and 54-month data, the maternal sensitivity composite was based on five 7-point global rating scales modified from Egeland and Heister (1995): supportive presence, respect for the child's autonomy, stimulation of cognitive development, quality of assistance, and hostility (reversed). Cronbach's alphas for the maternal and paternal sensitivity composites exceeded .75 at all ages of measurement. For purposes of this report, grand, crossage composites of mother's parenting and of father's parenting were created by averaging the respective maternal and paternal sensitivity composites obtained at each age of measurement after standardizing scores within age.

Intercoder reliability was determined by assigning two coders to $19-20 \%$ of the tapes randomly drawn at each assessment period. Coders were unaware of which tapes among their assignments were assigned to second coders, and reliability assessments were made throughout the period of coding. Intercoder reliability was calculated as the intraclass correlation (Winer, 1971). Reliability for the sensitivity composites was in excess of .80 at all ages of measurement.

Contextual antecedents: 1 Month. Regardless of whether a child was firstborn, the pregnancy was planned, and the child was White, three of the nine family background factors were selected to serve as contextual antecedents of family types in this inquiry. In addition, an income to needs ratio (income/needs) was computed as family income divided by the appropriate poverty threshold (US Department of Labor, Bureau of Labor Statistics, 1994) for each household size and number of children under 18 . The income/needs ratio is an index of family economic resources, with higher scores indicating greater financial resources in the household. (The income/needs ratio is an annually adjusted, per capita index comparing household income to federal estimates of minimally required expenditures for food and shelter. An income/needs ratio of 1.0 is the US government definition of poverty, so a ratio of 3.0 represents a per capita 
income three times the poverty level.) Maternal age and maternal education indexed, respectively, how old the mother was, and the number of years of schooling she had at enrolment. Father occupational status was based on a 13-point scale used in the 1990 US Census reflecting the prestige of the father's job, ranging (after reflection of original scoring) from 1 for the least prestigious job (i.e., handler, laborer, equipment cleaner, helper) to 13 for the most prestigious occupation (i.e., executive, administrative, managerial). Maternal depression was assessed using the Center for Epidemiological Studies Depression Scale (Radloff, 1977), a self-report measure designed to assess depressive symptomatology in the general population. Cronbach's alpha was .88 . Maternal childrearing attitudes was measured using the using the Modernity Scale (Schaefer \& Edgarton, 1985), a 30-item index of the degree of authoritarian versus democratic beliefs about raising children and the parenting role. A high score reflects progressive attitudes favoring self-directed child behavior and a low score traditional attitudes that the child should follow adult directives (e.g., a child should be seen and not heard). The alpha on this scale was .90. Finally, maternal social support was measured using the 11-item Relationships with Other People questionnaire (Marshall \& Barnett, 1991), in which the respondent rates support over the past month. The measure was designed to assess the individual's general perception of the availability of social support. Cronbach's alpha was in excess of .90 .

Developmental sequelae: First-grade child outcomes. First-grade teachers provided data on seven child outcomes used in this report. In addition, a standardized cognitive test was administered during first grade.

To assess the quality of the child's relationship with his/her teacher, first-grade teachers completed the Student-teacher Relationship Scale (STRS; Pianta, 2001). The STRS is a widely used indicator of a teacher's perceptions of the quality of their relationship with a specific child and accounts for unique variance in the prediction of social and academic outcomes in school-age children (e.g., Birch
\& Ladd, 1997; Hamre \& Pianta, 2001). Two composite indices were derived from the STRS and used in the present study as outcome indicators: conflict (assessing the degree of negative interactions and emotions involving the teacher and child) and closeness (assessing the degree of warmth, positive emotions, and open communication between child and teacher). Coefficient alpha for conflict is .93 and for closeness is .86 .

To assess problem behavior, teachers completed the 100-item Teacher Report Form (TRF) of the Child Behavior Checklist for children ages 5-18 (CBCL 5-18; Achenbach, 1991). Teachers rated how characteristic each behavior was of the child ( $0=$ not true, $1=$ sometimes true, $2=$ very true). The externalizing and internalizing problem behavior scores are the focus of this report. For both subscales raw scores were converted into standard $t$ scores, based on normative data for children of the same age. Research indicates that the CBCL 5-18 shows good test-retest reliability, and concurrent and predictive validity; it discriminates between clinically referred and nonreferred children and predicts problem scores over a 3-year period (Achenbach, 1991).

To assess social skills, teachers completed the Social Skills Questionnaire from the Social Skills Rating System (SSRS; Gresham \& Elliott, 1990). This instrument is composed of 38 items describing child behavior, each rated on a three-point scale reflecting how often the child exhibited each behavior. Items are grouped into four areas: cooperation (e.g., keeps room neat and clean without being reminded), assertion (e.g., makes friends easily), responsibility (e.g., asks permission before using someone else's property), and selfcontrol (e.g., controls temper when arguing with other children). The total score used in this report represents the sum of all 38 items, with higher scores reflecting higher levels of perceived social competence. Internal consistency was in excess of .80. The SSRS was normed on a diverse, national sample of children and shows high levels of internal consistency $($ median $=.90)$ and test-retest reliability (.75-.88) and moderate concurrent and predictive validity to other indices of social competence. 
Table 1. Intercorrelations between parenting and marital intimacy

\begin{tabular}{|c|c|c|c|c|}
\hline & \multicolumn{2}{|c|}{ Mother } & \multicolumn{2}{|c|}{ Father } \\
\hline & Parenting & $\begin{array}{l}\text { Marital } \\
\text { Intimacy }\end{array}$ & Parenting & $\begin{array}{l}\text { Marital } \\
\text { Intimacy }\end{array}$ \\
\hline \multicolumn{5}{|l|}{ Mother } \\
\hline Parenting & - & $.09 * *$ & $.39 * * *$ & .06 \\
\hline \multicolumn{5}{|l|}{ Father } \\
\hline Parenting & & & & $.08 *$ \\
\hline
\end{tabular}

Two methods were adopted to assess children's cognitive-academic achievement. First, teachers rated children's language and math skills using the Academic Skills questionnaire. The Language and Literacy scale deals with language skills related to listening, speaking, and early reading and writing skills. The Mathematical Thinking scale deals with the child's math skills, specifically, ability to perceive, understand, and utilize skills in solving mathematical problems. The Language and Literacy scale and the Mathematical Thinking scale had from 10 to 15 items each. Children's performance was rated on a 5-point scale, ranging from $1=$ not yet to $5=$ proficient the scale was designed to reflect the degree to which a child had acquired and/or chose to demonstrate the targeted skills, knowledge, and behaviors. Scale scores were computed by averaging across items making up each scale. Internal consistency was in excess of .90 for each subscale.

The second method for assessing cognitiveacademic achievement involved standardized testing. In the spring of first grade, children were administered four subtests from the Woodcock-Johnson Psycho-Educational Battery-Revised (Woodcock \& Johnson, 1989) which, for purposes of this report, were standardized (mean $=100, S D=15)$ and averaged: Letter-Word Identification, which assesses prereading skills in identifying isolated letters and words; Applied Problems, which measures skill in analyzing and solving practical problems in mathematics; Memory for Sentences which measures exactly what its label implies; and Picture Vocabulary, which measures children's ability to name objects depicted in a series of pictures. Items are presented in order of increasing difficulty and are scored $0=$ incorrect or no response or $1=$ correct response, with basal and ceiling levels established.

Further details about all data collection procedures are documented in the Manuals of Operation of the study (http://public.rti.org/ $\operatorname{secc} /)$.

\section{Results}

The results of this study are presented in four sections, one dealing with the intercorrelation of the marriage and parenting variables, a second focused upon the results of the latentclass analysis of these same variables, a third examining the developmental antecedents of the latent classes identified, and a fourth examining the putative developmental sequelae of these same latent classes.

\section{Intercorrelation of marriage, mothering, and fathering variables}

Even though it was our plan at the outset to subject the two marriage and two parenting variables to typological analysis, a preliminary correlational analysis was conducted to see how these variables related to one another across the entire subsample of two-parent families under study. Inspection of Table 1 reveals modest positive correlations between and among marriage and parenting variables. More specifically, mothers who scored high on parenting quality had partners who also tended to 
Table 2. BIC model fit statistics for latent-class analysis of marital quality and parenting sensitivity

\begin{tabular}{cccccc}
\hline \hline & \multicolumn{4}{c}{ Covariance Structure } \\
\cline { 2 - 3 } \multirow{2}{*}{$\begin{array}{c}\text { No. } \\
\text { Clusters }\end{array}$} & \multicolumn{2}{c}{ Class Independent } & & \multicolumn{2}{c}{ Class Dependent } \\
\cline { 2 - 3 } \cline { 5 - 6 } & Diagonal & Unrestricted & & Diagonal & Unrestricted \\
\hline \multirow{2}{*}{1} & 8,088 & 7,798 & & 8,088 & 7,798 \\
2 & 7,843 & 7,715 & & 7,675 & 7,596 \\
3 & 7,689 & 7,664 & & 7,559 & 7,589 \\
4 & 7,671 & 7,668 & & 7,513 & 7,587 \\
5 & 7,661 & 7,677 & & 7,503 & 7,637 \\
6 & 7,664 & 7,674 & & 7,520 & 7,704 \\
\hline \hline
\end{tabular}

score high, with the same being true with respect to marital quality. Correlations between marriage and parenting were typically low, though positive, and significant.

\section{Latent-class analysis of marriage and parenting variables}

The relative modesty of the significant correlations displayed in Table 1 suggested, at least initially, that even though there is some degree of positive association between and among marriage and parenting measures, it is by no means substantial. It seems conceivable, however, that the data displayed in Table 1 obscure as much as they illuminate the interrelation of marriage and parenting variables. This is because paternal sensitivity may be only modestly associated with marital quality because in one subset of households there is no actual association, whereas in others there is a strong positive association, yet in others there may actually be a negative association. To explore such possibilities, the individual marriage and parenting scores were subjected to latent-class analysis, using the latent-class analysis software Latent Gold (Vermunt \& Magidson, 2000).

Latent-class analysis can be considered a probabilistic extension of K-means cluster analysis. The advantage of the latent class approach is that, unlike $\mathrm{K}$-means cluster analysis, it is model-based and permits the use of statistical criteria for deciding among different cluster solutions (Vermunt \& Magidson, 2000). The method is related to mixture models and involves minimizing within-cluster covari- ances between indicators and maximizing variance between different clusters. The analyst may choose among solutions with different numbers of clusters by way of the Bayesian information criterion (BIC) information criterion (Vermunt \& Magidson, 2000). The model with the smallest BIC is generally preferred because it indicates a good balance of model fit and parsimony (relatively fewer parameters). In arriving at an optimal cluster solution it is preferable to explore several variants of model structure, which sequentially relax assumptions regarding the covariance structure of the indicators (Vermunt \& Magidson, 2000). The most restrictive model is one in which indicators are assumed to be independent within clusters and error variances are assumed to be independent of class. The next set of models relaxes the latter assumption and allows for cluster dependent differences in error variance. The final set of models used in this report further relaxes model assumptions by allowing an unrestricted variance-covariance structure within clusters and class dependent errors.

The model BICs are shown in Table 2 for one to six class solutions under each of these model restrictions. As can be seen from Table 2, the best fitting solution was a five-class one, with class-dependent error variances but independence of indicators within groups (BIC = 7,503). A five-group solution was thus selected and each case was assigned to the group to which they had the highest estimated probability of belonging.

Table 3 presents the means (and standard deviations) of the marriage and parenting vari- 
Table 3. Standardized marriage and parenting scores by family type

\begin{tabular}{lccccc}
\hline \hline & \multicolumn{5}{c}{ Family Type } \\
\cline { 2 - 6 } & $\begin{array}{c}\text { Consistently } \\
\text { Supportive } \\
(n=125)\end{array}$ & $\begin{array}{c}\text { II } \\
\text { Consistently } \\
\text { Moderate } \\
(n=360)\end{array}$ & $\begin{array}{c}\text { III } \\
\text { Good Parenting } \\
\text { Poor Marriage } \\
(n=155)\end{array}$ & $\begin{array}{c}\text { Poor Parenting } \\
\text { Good Marriage } \\
(n=54)\end{array}$ & $\begin{array}{c}\text { Consistently } \\
\text { Risky } \\
(n=135)\end{array}$ \\
\hline M. Sensitivity & .48 & .24 & .50 & -.51 & -.62 \\
F. Sensitivity & .58 & .18 & .33 & -.99 & -.95 \\
M. Marriage & .86 & .19 & -.80 & .81 & -.60 \\
F. Marriage & .99 & .24 & -1.09 & .83 & -.65 \\
\hline
\end{tabular}

ables for each latent class that emerged in the five-group solution. The first class is labeled "Consistently Supportive" because the mean scores for the 125 families assigned to this group were among the highest, if not the highest, on all four parenting and marriage variables subjected to latent-class analysis: maternal sensitivity, paternal sensitivity, father marriage, and mother marriage. Class II is labeled "Consistently Moderate" because the 360 families assigned to this class evinced intermediate scores, relative to the other detected classes, on all four family measures. Class V is labeled "Consistently Risky" because the means scores for the 135 families assigned to this class were among the lowest, if not the lowest, on all four family variables.

The remaining two subgroups could not be scaled easily (and thus labeled) in linear terms (i.e., risky-moderate supportive) on all four family measurements subject to latent-class analysis as they evinced more of a mosaic of strengths and weaknesses. Class III was labeled "Good Parenting/Poor Marriage" because the 155 families assigned to this class had reasonably positive parenting scores but the lowest marriage scores. Class IV proved to be the mirror image of the one just described because for these 54 families it was marriage scores that were positive and parenting scores that were negative. We thus labeled this subgroup "Poor Parenting/Good Marriage." It should be kept in mind that all such value-laden labeling (e.g., good parenting, poor marriage) is based on the relative standing of the subgroups to one another, not some absolute standard (e.g., clinical cutoff).
Consideration of the nature of the subgroups identified led us to focus upon a restricted set of pairwise comparisons when it came to examining in subsequent analyses developmental antecedents and sequelae of the just-described family types. Thus, in the remainder of the article we set out to answer very targeted questions rather than compare every single group with every single other group (or sets of groups). The first question concerned differences between the first three groups described above. Not surprisingly, it was expected that children raised in the Consistently Supportive families would function more competently than those raised in the Consistently Moderate families and that children from these latter households would function more competently than those raised in Consistently Risky ones.

The second question concerned differences between families that contrasted markedly in their marital and parental strengths and thus led us to compare the Good-Parenting/PoorMarriage group with the Poor-Parenting/GoodMarriage group. Working under the assumption that parenting has greater impact upon children than marriage, we predicted that children growing up in the Good-Parenting/ Poor-Marriage families would look more competent than those growing up in households characterized as Poor Parenting/Good Marriage.

The third and fourth sets of comparisons were designed to address issues of whether good parenting or good marriage, respectively, "added value," developmentally speaking, when a child resided in a home that already 
evinced family strengths. In the first instance, then, comparisons sought to determine whether a well-functioning marriage was associated with enhanced child development in the face of good parenting by comparing children in the Consistently Supportive families with those from the Good-Parenting/Poor-Marriage families. To the extent that good marriage provided additional developmental support for the child, it would be expected that the children from the Consistently Supportive families would outperform those growing up in the Good-Parenting/Poor-Marriage families. The second set of tests pertaining to "added value" sought to determine whether good parenting was associated with enhanced child development in the face of a well-functioning marriage by comparing children in the Consistently Supportive families with those from the PoorParenting/Good-Marriage families. To the extent that good parenting provided additional developmental support for the child, it would be expected that the children in the Consistently Supportive families would outperform those in the Poor-Parenting/GoodMarriage families.

The fifth and sixth sets of comparisons followed similar logic, but were designed to address issues of whether good parenting or good marriage, respectively, protected against the presumed developmental costs of growing up in a home which evinced family weaknesses or vulnerabilities. In the first instance, then, comparisons sought to determine whether a well-functioning marriage was associated with enhanced child development in the face of poor parenting by comparing children in the Consistently Risky families with those from the Poor-Parenting/Good-Marriage families. To the extent that good marriage functioned protectively, it would be expected that the children in the Good-Marriage/Poor-Parenting families would outperform those in the Consistently Risky families. The second set of tests pertaining to protective effects of family subsystems sought to determine whether good parenting was associated with enhanced child development in the face of a poorly functioning marriage by comparing children in the Consistently Risky families with those from the Good-Parenting/Poor-Marriage families. To the extent that good parenting functioned protectively, it would be expected that the children in the Good-Parenting/Poor-Marriage families would outperform those in the Consistently Risky families.

\section{Contextual antecedents of family types: Select comparisons}

Before testing the hypotheses just outlined pertaining to children's functioning in first grade as a function of the type of family in which they were raised during their infancy, toddler, and preschool years, we report differences between select pairs of groups (see above) on demographic and ecological factors measured when families first enrolled in the study when children were 1 month of age and thus before the marriage and parenting assessments were made. Recall that the purpose of these analyses was to identify preexisting differences between subgroups that would need to be taken into account when subsequently examining relations between family type and child functioning. Thus, they followed the plan delineated above with respect to the select pairwise comparisons that would be undertaken. Table 4 presents the means (and standard deviations) for the five family subgroups on the set of antecedent measurements chosen for analysis: child birth order (i.e., percent firstborn), planned pregnancy (i.e., percent planned), child race (i.e., percent White), family income/ needs, mother's age, father's occupational status, maternal depression, maternal childrearing attitudes, and maternal social support. As in Table 3, means and standard deviations of all groups are presented so that interested readers can make any of the many statistical comparisons that remain possible but are not the subject of this report.

Linear contrasts and chi-square tests were used to evaluate the general proposition that the Consistently Supportive group would possess more resources than the Consistently Moderate group, which would possess more resources than the Consistently Risky group (i.e., Consistently Supportive $>$ Consistently Moderate $>$ Consistently Risky). Results revealed, not surprisingly, that less risk was associated with greater social, psychological, 
Table 4. Contextual antecedents by family type

\begin{tabular}{|c|c|c|c|c|c|}
\hline \multirow[b]{2}{*}{$\begin{array}{l}\text { Contextual } \\
\text { Antecedents }\end{array}$} & \multicolumn{5}{|c|}{ Family Type } \\
\hline & $\begin{array}{c}\text { I } \\
\text { Consistently } \\
\text { Supportive } \\
(n=125)\end{array}$ & $\begin{array}{c}\text { II } \\
\text { Consistently } \\
\text { Moderate } \\
(n=360)\end{array}$ & $\begin{array}{c}\text { III } \\
\text { Good Parenting } \\
\text { Poor Marriage } \\
(n=155)\end{array}$ & $\begin{array}{c}\text { IV } \\
\text { Poor Parenting } \\
\text { Good Marriage } \\
\quad(n=54)\end{array}$ & $\begin{array}{c}\mathrm{V} \\
\text { Consistently } \\
\text { Risky } \\
(n=135)\end{array}$ \\
\hline Firstborn $(\%)$ & 42.4 & 46.4 & 43.9 & 51.9 & 38.5 \\
\hline Planned pregnancy $(\%)$ & 69.4 & 60.9 & 64.5 & 42.6 & 37.0 \\
\hline White $(\%)$ & 94.4 & 92.2 & 95.5 & 72.2 & 88.9 \\
\hline Income: needs & $3.96(2.95)$ & $3.06(2.64)$ & $3.69(2.65)$ & $2.89(2.51)$ & $1.85(1.77)$ \\
\hline M. Age & $29.38(4.23)$ & $29.49(5.35)$ & $30.73(4.78)$ & $27.78(6.25)$ & $26.96(6.00)$ \\
\hline F. Occupational status & $9.43(3.28)$ & $7.71(4.11)$ & $8.83(3.70)$ & $6.63(4.02)$ & $5.60(4.14)$ \\
\hline M. Depression & $7.24(6.47)$ & $10.14(8.17)$ & $11.40(8.92)$ & $10.56(8.72)$ & $15.16(9.77)$ \\
\hline M. Childrearing attitudes & $33.10(2.97)$ & $33.39(3.35)$ & $34.01(3.07)$ & $32.70(3.22)$ & $31.42(3.59)$ \\
\hline M. Social support & $5.39(0.43)$ & $5.22(0.58)$ & $5.20(0.57)$ & $5.22(0.67)$ & $4.97(0.60)$ \\
\hline
\end{tabular}

and economic resources. More specifically, this linear effect was significant and in the expected direction (i.e, reverse order for measurements of poor functioning like depression) for rate of planned pregnancies, $\chi(1)=27.1, p<$ .001 , income $/$ needs, $t(802)=6.56, p<.001$, maternal age, $t(824)=3.71, p<.001$, father occupational status, $t(766)=7.53, p<.001$, social support, $t(823)=5.66, p=.001$, maternal depression, $t(824)=7.59, p<.001$, and maternal progressive childrearing attitudes, $t$ $(822)=4.10, p<.001$

The second set of comparisons between the Good-Parenting/Poor-Marriage and the PoorParenting/Good-Marriage groups (i.e., III vs. IV) indicated that the former group scored higher than the latter in terms of maternal age, $t(824)=3.55, p<.001$, father's occupational status, $t(766)=3.94, p<.001$, and maternal progressive childrearing attitudes. The GoodParenting/Poor-Marriage group was also more likely to have planned their pregnancy, $\chi^{2}(1)=$ $7.95, p=.005$, and to be White, $\chi^{2}(1)=$ 23.01, $p<.001$.

The third set of comparisons between the Consistently Supportive and the GoodParenting/Poor-Marriage groups (i.e., I vs. III), and pertaining to the "added-value" hypothesis, indicated that mothers in the latter group were somewhat older, $t(824)=2.12, p=.034$, and scored higher in terms of depression, $t$ $(824)=4.11, p<.001$, and lower in terms of social support, $t(824)=2.59, p=.002$. Mothers in this latter group also appeared to have more progressive childrearing attitudes, $t(822)=2.31, p=.013$.

The fourth comparison, mirroring the third and also relevant to the "added-value hypothesis," contrasted the Consistently Supportive group with the Poor-Parenting/Good-Marriage group (i.e., I and IV). The Poor-Parenting/ Good-Marriage group was found to score lower on income/needs ratio, $t(802)=2.43, p=$ .020 , and paternal occupational status, $t(766)=$ $4.11, p<.001$, but higher in terms of maternal depression, $t(824)=2.51, p=.014$. This group was also less likely to have planned their pregnancy, $\chi^{2}(1)=11.35, p=.001$, and was more likely to be of non-White ethnicity, $\chi^{2}(1)=17.21, p<.001$.

The fifth comparison contrasted the GoodParenting/Poor-Marriage group with the Consistently Risky group (i.e., III vs. V) and was pertinent to the "protective-buffering" hypothesis. In this case, the two groups differed significantly from each other on every antecedent variable except birth order, $\chi^{2}(1)=.85, p=$ .36. Not surprisingly, it was the Consistently Risky group that scored more negatively for the indices of contextual-risk/support variables, with lower income to needs, $t(802)=$ $6.05, p<.001$, lower maternal age, $t(824)=$ $6.08, p<.001$, lower paternal occupational status, $t(766)=6.68, p<.001$, higher levels 
Table 5. Development sequelae by family type

\begin{tabular}{|c|c|c|c|c|c|}
\hline \multirow[b]{2}{*}{$\begin{array}{c}\text { Developmental } \\
\text { Sequelae }\end{array}$} & \multicolumn{5}{|c|}{ Family Type } \\
\hline & $\begin{array}{c}\text { I } \\
\text { Consistently } \\
\text { Supportive } \\
(n=125)\end{array}$ & $\begin{array}{c}\text { II } \\
\text { Consistently } \\
\text { Moderate } \\
(n=360)\end{array}$ & $\begin{array}{c}\text { III } \\
\text { Good Parenting } \\
\text { Poor Marriage } \\
(n=155)\end{array}$ & $\begin{array}{c}\text { IV } \\
\text { Poor Parenting } \\
\text { Good Marriage } \\
(n=54)\end{array}$ & $\begin{array}{c}\text { V } \\
\text { Consistently } \\
\text { Risky } \\
(n=135)\end{array}$ \\
\hline $\mathrm{T}-\mathrm{C}$ conflict & $9.53 \quad(4.20)$ & 10.27 (4.88) & 10.67 (4.69) & $10.92 \quad(5.27)$ & $11.66 \quad(5.18)$ \\
\hline $\mathrm{T}-\mathrm{C}$ closeness & $33.69 \quad(5.36)$ & $34.44 \quad(4.71)$ & $34.66 \quad(4.92)$ & $33.79 \quad(5.05)$ & 33.61 (4.98) \\
\hline TRF internalizing & $48.90 \quad(4.19)$ & $48.71 \quad(8.66)$ & $48.95 \quad(9.28)$ & $50.31 \quad(9.13)$ & $49.77 \quad(9.64)$ \\
\hline TRF externalizing & $47.64 \quad(7.90)$ & $49.32 \quad(8.17)$ & $49.83 \quad(8.45)$ & $50.31 \quad(8.18)$ & $52.54 \quad(9.22)$ \\
\hline Social skills total & 107.7 (12.58) & $105.6 \quad(13.02)$ & 104.2 (13.49) & $102.0 \quad(12.44)$ & $100.1 \quad(13.95)$ \\
\hline Language skill & $3.56(0.78)$ & $3.41(0.95)$ & $3.70(0.82)$ & $3.20(1.08)$ & $3.17 \quad(0.99)$ \\
\hline Math skill & $3.41 \quad(0.92)$ & $3.27 \quad(0.92)$ & $3.44 \quad(0.90)$ & 3.04 (1.09) & $3.05 \quad(0.94)$ \\
\hline $\begin{array}{l}\text { Cognitive } \\
\text { assessment }{ }^{a}\end{array}$ & $0.396(0.807)$ & $0.147(0.894)$ & $0.440(0.852)$ & $-0.346(1.04)$ & $-0.463(1.01)$ \\
\hline
\end{tabular}

Note: T-C, Teacher-Child; TRF, Teacher Request Form.

${ }^{a}$ Standardized sum of Woodcock-Johnson Memory for Names, Memory for Sentences, Incomplete words, Picture vocabulary, Letter-Word Identification, Applied problems, and Word Attack.

of maternal depression, $t(824)=3.80, p<$ .001 , lower levels of maternal social support, $t$ $(824)=3.32, p<.001$, less progressive maternal child-rearing attitudes, $t(822)=6.67, p<$ .001 , and a higher rate of unplanned pregnancy, $\chi^{2}(1)=21.82, p<.001$. The Consistently Risky group was also more likely to be of non-White ethnicity, $\chi^{2}(1)=26.71, p<$ .001 .

The sixth and final comparison, which is also relevant to the protective-buffering hypothesis, contrasted the Poor-Parenting/ Good-Marriage group with the Consistently Risky group. The Poor-Parenting/GoodMarriage group did not differ significantly from the Consistently Risky group in terms of maternal age, $t(824)=.97, p=.33$, paternal occupational status, $t(766)=1.51, p=.13$, birth order, $\chi^{2}(1)=2.81, p=.094$, planned pregnancy, $\chi^{2}(1)=.523, p=.48$, or non-White ethnicity, $\chi^{2}(1)=.07, p=.79$. The PoorParenting/Good-Marriage group did score more highly, however, on family income/ needs ratio, $t(802)=2.42, p=.010$, maternal social support, $t(824)=2.69, p=.002$, and maternal progressive childrearing attitudes, $t$ $(822)=2.42, p=.019$. This group also experienced lower levels of maternal depression than the Consistently Risky group, $t(824)=$ $3.40, p=.001$.
Developmental sequelae of family types:

Select comparisons

Between-group comparisons identical to those just reported were next carried out on the set of first-grade developmental outcomes: teacher-child conflict and closeness, TRF internalizing and externalizing problems, social skills (total), language and math skills, and tested cognitive competence. In each case, we report first the significant differences that emerged between groups on these first-grade measurements without controlling for differences that emerged in the analysis of developmental antecedents, followed by a second set of results pertaining to the same group differences in children's functioning once significant between-group differences on developmental antecedents were taken into account. The full set of means and standard deviations for these developmental sequelae are shown in Table 5.

Linear contrasts testing the proposition that children in the Consistently Supportive families would evince more competencies and fewer problems than those in the Consistently Moderate families who would likewise outperform those in the Consistently Risky families provided evidence consistent with this proposition in the case of teacher-child conflict, 
$t(769)=3.51, p=.001$, externalizing problems, $t(770)=4.57, p<.001$, social skills, $t(767)=4.53, p<.001$, language and mathematical skills, $t(770)=2.63, p=.001$; $t(769)=2.99, p=.003$, respectively, and Woodcock-Johnson cognitive test performance, $t(780)=7.37, p<.001$. When the same group comparisons were rerun controlling for the multiple background variables on which these groups differed, significant group differences remained for externalizing behavior problems, social skills and the Woodcock-Johnson total score. The other previously significant differences were no longer significant once background antecedent factors were controlled.

The second set of comparisons between the Good-Parenting/Poor-Marriage and the Poor-Parenting/Good-Marriage groups (i.e., subgroup II vs. IV) indicated that children faired somewhat better growing up in households characterized by good parenting rather than good marriage, when only marriage or parenting were clearly positive. More specifically, children from the Good-Parenting/PoorMarriage group scored higher on language skills, $t(771)=3.41, p=.001$, and mathematical skills, $t(769)=2.71, p=.007$, and on the formal cognitive assessment, $t(780)=5.37, p<.001$, than did children from the Poor-Parenting/Good-Marriage group. When controls were made for antecedent differences associated with these groups, the difference in mathematical skills was no longer significant, but the differences in language skills and formal cognitive performance remained significant.

The third and fourth sets of comparisons addressed the added-value hypothesis. The third set of comparisons between the Consistently Supportive and Good-Parenting/PoorMarriage groups revealed only a few significant differences between children in these two groups. Children from the Consistently Supportive group scored significantly lower on externalizing problems, $t(770)=2.13, p$ $=.030$, and higher on social skills, $t(767)=$ $2.17, p=.029$, than those from the GoodParenting/Poor-Marriage group. These same differences held when background differences between groups were controlled.
The fourth set of comparisons contrasted the Consistently Supportive group with the Poor-Parenting/Good-Marriage group. Children from the Consistently Supportive group showed more positive outcomes for teacher rated social skills, $t(767)=2.61, p=.009$, language skills, $t(770)=2.37, p=.018$, mathematical skills, $t(769)=2.38, p=.017$, and formal cognitive performance, $t(780)=4.88$, $p<.001$, than those from the Poor-Parenting/ Good-Marriage group. After controls were included for background factors that discriminated these groups in earlier analyses, the differences in language and mathematical skills were no longer significant, but the differences in social skills and formal cognitive performance remained significant.

The fifth and sixth sets of comparisons address the protective-buffering hypothesis. The fifth contrast, comparing the GoodParenting/Poor-Marriage group with the Consistently Risky group, revealed significantly better child outcomes for the former group on externalizing behavior problems, $t(770)=$ 2.66, $p=.008$, social skills, $t(767)=2.58$, $p=.010$, language and mathematical skills, $t$ $(770)=4.74, p<.001$; and $t(769)=3.49$, $p=.001$, respectively, and formal cognitive performance, $t(780)=8.27, p<.001$. Only the differences in language skills and cognitive performance remained once antecedent differences were taken into account.

The final contrast compared the GoodMarriage/Poor-Parenting group with the Consistently Risky group. These two groups did not differ on any of the measured child outcomes (with or without controls for antecedent background characteristics).

\section{Discussion}

A now extensive body of research clearly demonstrates that individual differences in marital quality and parenting are positively associated with one another Indeed, Erel and Burman's (1995) meta-analysis of 68 relevant studies yielded an average effect size for the association between measures of marriage and parenting of .46. Although there has been repeated indication in individual studies that the relation between marriage and parenting is 
somewhat stronger for fathers than for mothers (e.g., Belsky, 1979; Belsky et al., 1991; Cowan \& Cowan, 1992; Goldberg \& Easterbrooks, 1984), the meta-analysis did not detect enough support for this observation to afford a strong empirical conclusion regarding differential relations between marital quality and parenting for mothers/wives and husbands/fathers. The results of this meta-analysis, as well as studies reported subsequent to it (for review, see Belsky \& Jaffee, in press), make clear in any event that the marriage-parenting association, although statistically reliable and even perhaps substantial, is by no means perfect. It was this empirical observation, coupled with the extensive typological thinking of family-systems' theorists about distinctive types of families (Minuchin, 1974), that served as impetus for the research presented in this report.

The fact that the marriage-parenting association is limited suggested to us that the detected magnitude of the association may, in fact, mask substantial diversity in the way in which individual differences in marriage and parenting go together in families. In particular, it seemed conceivable that the size of the relation may derive from the fact that in some households marriage and parenting are more or less tightly (and positively) coupled, with high or low levels of functioning in one domain covarying, respectively, with high or low levels of functioning in the other, whereas in other households these domains of relationship functioning may be inversely related or even entirely unrelated. Not inconsistent with this possibility was the fact that the association between marriage and parenting in the studies included in the aforementioned meta-analysis ranged from -0.52 to 2.30 . Upon recognizing that it has been the linear association between indices of marriage and parenting that has been the principal focus of most relevant studies to date, one must acknowledge that this informative body of knowledge may, nevertheless, fail to illuminate the complex nature of the marriage-parenting interrelation.

To explore this possibility, data collected on marriage and parenting during the infant, toddler, and preschool phases of the NICHD Study of Early Child were subject to latentclass analysis, a statistical approach that can be considered a probabilistic extension of $\mathrm{K}$-means cluster analysis that readers may be more familiar with, in hopes of detecting meaningful types of families, insofar as marriage and parenting are concerned. One of the great strengths of the NICHD study is the sizeable sample and the availability of longitudinal data; the latter feature enabled us to consider in this study both antecedents and developmental sequelae of different patterns of marriage and parenting.

Such strengths, of course, were offset by at least two notable weaknesses. The first is that our latent-class analysis was, indisputably and admittedly, exploratory in nature, informed by the data at hand rather than a compelling theory of what marriage-parenting patterns might be detected. This is the reason that, in the core analysis, we chose to make select, post hoc comparisons between pairs of marriageparenting types rather than examine differences across all the identified types on all the contextual antecedents and child "outcomes." That is, in proceeding as we did, we endeavored to constrain the exploratory nature of the inquiry and reduce the likelihood that results generated would be a function of chance.

The second notable weakness of our investigation concerned limitations of the data available for analysis. Although the variety of variables conceptualized as antecedents and developmental sequelae in this inquiry represent a clear strength of the study, as were the repeated assessments of mothering, the fact that the fathering of many men was measured only once undermines the reliability of some of the measurements obtained. But perhaps even more limiting than this feature of the data collected were the very limited measurements of marital quality. Few would argue with the notion that this investigation could have benefited from a richer variety of measures that would fall under the rubric of marital quality (e.g., frequency of conflict, marital power). Unfortunately, as the larger investigation from which the current study derives involved the measurement of numerous constructs, the breadth and depth of marital assessments were inevitably constrained, and severely so.

Our exploratory typological analyses of the interrelation of marriage and parenting pro- 
ceeded, it will be recalled, in three steps after examining linear associations between measures of marriage and parenting for the entire sample. The first step focused upon identifying, by means of latent-class analysis, seemingly different types of families using measurements of each parents' (observed) parenting and their self appraisal of their "marital" relationship (i.e., marital intimacy). The second and third sets of analyses addressed antecedents, and thus potential determinants of the family types, using individual parent and family measurements obtained when children were 1 month old, and developmental sequelae and thus potential consequences of growing up in particular types of families, using eight diverse measures of child social and cognitive functioning in the first grade. We purposefully use the term "antecedent" rather than "determinant" and "sequelae" rather than "outcome" (unless placed in quotations) in characterizing our measurements because from both a theoretical and empirical standpoint it is problematic to presume that what we are detecting are standard cause and effect relations. All we can claim to have illuminated in this inquiry are statistical associations involving family factors measured before we assessed marriage and parenting and measures of child functioning assessed after we measured marriage and parenting. Not only would it be mistaken to infer causation from such data given that even temporally ordered longitudinal associations remain correlational (and thus not causal) in nature, but because doing so would contradict much of what is central to family-systems' thinking. After all, the family-systems' perspective presumes that causal relations among the elements of the system (i.e., marriage, parenting, child development) are circular rather than linear; each element both affects and is affected by the other elements (Grych, 2002).

\section{Marital typology and select comparisons}

Results of the latent-class analysis of marriage and parenting data revealed five seemingly meaningful types of families and provided evidence that these five subgroups, rather than fewer or more, best represented the variation in covariance between marriage and parenting measures. Recall that three of the five groups seemed to rank from least to-most supportive of child well-being because scores on marriage and parenting across these three groups ranked similarly, from low to moderate to high, but that in the case of the remaining two groups, comprising approximately one quarter of the sample, this was not the case. It seemed likely that the three-quarters of the sample assigned to the groups labeled Consistently Supportive, Consistently Moderate, and Consistently Risky were responsible for the positive correlation between marriage and parenting that emerged when data from the entire sample was subject to analysis (i.e., Table 1). After all, across these three groups, as marital quality increased, so did, in the main, parental sensitivity (or vice versa). In fact, when we reran the correlations presented in Table 1 deleting all but the 620 families included in these three groups, the correlation between marriage and parenting for wives was $.37(p<.001)$ and for husbands $.39(p<$ $.001)$, each noticeably larger than the respective $.09(p<.01)$ and $.08(p<.05)$ associations presented in Table 1 . We now turn attention first to the nature of, and linear comparisons involving, these three groups, before considering the other two groups that manifested "inconsistency" with respect to the quality of marriage reported and the quality of parenting observed.

Three groups manifesting consistency across marriage and parenting. The group that scored among the lowest, if not the lowest, on maternal and paternal measurements of parenting and marital quality, comprising some $16 \%$ of the sample, was labeled Consistently Risky given our presumption that these families would manifest the most contextual risk and that children in these families would function most poorly in the first grade. The group labeled Consistently Supportive, which comprised $15 \%$ of the sample, manifested the reverse profile, scoring highest or among the highest on the marriage and parenting measures of both mothers and fathers. We presumed that children growing up in such households would be exposed to the most con- 
textual support and develop most competently. A third group whose marriage and parenting scores were more or less intermediate between these two other groups and comprised some $43 \%$ of the sample was thus labeled Consistently Moderate. It was our prediction that scores for this group on both contextual antecedents and developmental sequelae would fall in between those from the other two groups of families just considered.

As predicted, there was consistent evidence that contextual risk increased more or less linearly as one moved from the Consistently Supportive to Consistently Moderate to Consistently Risky groups. Indeed, this proved to be the case to a statistically significant extent with respect to rate of planned pregnancies, income to needs, maternal age, father occupational status, maternal social support, and maternal progressive childrearing attitudes and maternal depression. It is seemingly related that, as one moved across the same three groups of families, children from these households evinced greater teacher-child conflict, greater externalizing problems, poorer social skills, poorer language and math skills, and lower cognitive performance on the WoodcockJohnson test battery. To be noted, however, is that once controls were implemented for family background factors on which the three marriage-parenting groups differed, only the differences between marriage-parenting groups on externalizing problems, social skills, and the standardized cognitive assessment remained statistically significant.

In some respects, the just summarized findings provide preliminary validation for the marriage-parenting typology under consideration. After all, they show that families that manifest greater marital and parenting strengths experience less contextual risk and raise children who evince greater cognitive and social competencies and fewer problems than children who experience fewer marital and parental strengths; and that, most significantly, important group differences in children's functioning remain even after taking into consideration multiple family background factors. In sum, then, the first set of results paint a picture that is likely to be familiar to most students of child development and of develop- mental psychopathology, one in which multiple social risk factors go hand in hand with difficulties in the marital relationship and poor parenting, which themselves prefigure relatively poor socioemotional and cognitive outcomes for children. Within the limits of the study design, these latter results clearly suggest that patterns of marriage and parenting are of developmental significance for children's development. Of course, this conclusion must be tempered by the following facts: the data under consideration are nonexperimental in nature, the design of the study fails to take into consideration the shared genetic heritage of parents and children, and by no means have all conceiveable family background factors been controlled.

Two groups manifesting inconsistency across marriage and parenting. The remaining $26 \%$ of the sample that was not assigned to one of the first three groups just considered served to reduce the positive linear associations between marriage and parenting in the full sample. This was because they manifest, within each of the two groups, contrasting patterns of marital and parenting quality. Whereas one group evinced relatively high parenting scores and low marital scores, and was thus labeled GoodParenting/Poor-Marriage, a fifth group manifest a reverse profile in which low parenting scores went together with high marriage scores (labeled Poor-Parenting/Good-Marriage).

The nature of the Good-Parenting/PoorMarriage group merits some special consideration given a family-systems' perspective and the fact that it comprised almost $20 \%$ of the sample (in contrast to the Poor-Parenting/ Good-Marriage group, which accounted for less than $7 \%$ of the sample). Are these the kinds of households in which, in the face of (relatively) unsatisfying marriages, each parent invests disproportionately in the parentchild subsystem, perhaps even endeavoring to find there the emotional closeness that seems lacking in the marital subsystem? Family systems' theorists have been alert to this kind of "detouring" of emotional investments in troubled family systems for quite some time (Grych, 2002; Johnson, 2003; Kerig, 1995). Were this speculative analysis on target, one 
might expect to find evidence of vulnerability on the part of children in these households. Some limited evidence to this effect did emerge from this inquiry. Recall that children in the Good-Parenting/Poor-Marriage group evinced more externalizing problems and fewer social skills than those in the Consistently Supportive group. The fact, however, that these same children did not differ from those growing up in these seemingly best-functioning families on the remaining six first-grade measurements, including most especially the measure of internalizing problems, suggests caution before embracing the conclusion that the group differences just mentioned chronicle adverse effects of marital detouring and compensatory emotional investment by spouses in the parentchild relationship. So, too, perhaps, does the fact that on several measurements the children in the Good-Parenting/Poor-Marriage group outperformed children from the Consistently Risky and from the Poor-Parenting/GoodMarriage groups (see Table 5).

These latter findings pertaining to the contrast between the Good-Parenting/PoorMarriage and Poor-Parenting/Good-Marriage groups, it should be recalled, are consistent with the hypothesis that if only marriage or parenting proved to be a family strength, then children would function better when it was parenting rather than marriage that proved to be the locus of developmental resources in the family. Recall further that this prediction was based on the proposition that parenting would be more influential with respect to child development than marriage because the child more directly experiences the quality of parenting than the quality of the marital relationship, all other things being equal. In the main, the findings contrasting the two "inconsistent" groups suggest that, assuming other things remain unaltered, if some subsystem of the family has to be weak, it is better for the child that it be the husband-wife rather than the parent-child relationship. Such a conclusion would seem to coincide with results of divorce research indicating that children are buffered from the effects of marital dissolution in large measure if parenting is not seriously compromised in the face of marital problems (Hetherington, Bridges, \& Insabella, 1998).
In view of the fact that the developmentalsequelae data do not provide unambiguous support for the prospect that compensatory investment in the parent-child relationship in the face of marital tensions or dissatisfactions characterizes the family dynamics of the GoodParenting/Poor-Marriage group, the question arises as to what enables the adults in these households to keep marital difficulties, dissatisfactions, and/or stressors from "spilling over" and perhaps even "contaminating" the parentchild relationship. That is, what affords these relatively dissatisfied couples the strength to maintain what appear to be healthy boundaries between marriage and parenting subsystems? Some insight may be derived from the results of the analyses of contextual antecedents. Recall that relative to both the Consistently Supportive and Poor-Parenting/ Good-Marriage groups, the Good-Parenting/ Poor-Marriage group comprised mothers who were somewhat older, and perhaps more psychologically mature, and who held somewhat more progressive childrearing attitudes. The Good-Parenting/Poor-Marriage group also included fathers with higher status occupations and evinced higher rates of planned pregnancies than did the Poor-Parenting/GoodMarriage group. It could be just such individual and family characteristics that enable some parents to maintain supportive patterns of parenting even in the face of relatively unsatisfactory marital relationships. To the extent that this is indeed the case, it cautions against equating marriage-parenting patterns reflective of relatively poor marital functioning coupled with relatively competent mothering and fathering with family-system dysfunctions of the kind implied by notions of marital detouring and compensatory emotional investment in parenting.

Added-value and protective-buffering comparisons. In addition to comparing (a) groups of families that manifest seemingly linear variation in the quality of marriage and parenting and (b) groups that contrasted dramatically with one another with respect to the locus of (relative) family strengths, two additional sets of analyses were carried out that involved select comparisons of groups used in the first set of comparisons with those used in the second set. 
One series of comparisons was designed to determine whether two sources of family strength added value developmentally over a single source of strength, whereas the other series of comparisons was designed to determine whether a single source of family strength provided developmental "protection" in comparison with the (relative) absence of (measured) family strengths. Pertinent results are discussed in turn.

Added-value comparisons. Some modest evidence emerged that the children growing up in households in which both parenting and marriage appeared to be supportive of development (i.e., Consistently Supportive families) functioned better than those growing up in households in which only parenting or marriage seemed supportive of development. More specifically, (a) the fact that children in the former families were rated lower on externalizing problems and higher on social skills by teachers than those from Good-Parenting/ Poor-Marriage families, even after controlling for background differences between these types of families, and (b) that the same was true with respect to social skills and performance on the Woodcock-Johnson cognitive test battery when the Consistently Supportive group was compared with the Poor-Parenting/ Good-Marriage group provides some evidence of added value when families can be characterized by two sources of strength rather than only a single source of strength. The fact, however, that children in the Consistently Supportive group did not outperform those from these other two groups when 12 other comparisons was made should caution against drawing too strong a conclusion with respect to the "added-value" hypothesis.

The countervailing fact that 8 of these 12 comparisons that proved insignificant involved four child "outcomes" (i.e., teacher-child closeness and conflict, internalizing problems, math skills) that were totally insensitive to any (of the many) group comparisons conducted that controlled for family background factors should not be overlooked, however. Indeed, these across the board null findings raise the prospect that some aspects of development may be more sensitive to patterns of marriage and parenting than others (i.e., externalizing problems, social skills, language skills, cognitive test performance). Importantly, it does not simply appear to be the case that it is social or cognitive outcomes or teacher-based ratings that appear to be less sensitive to variation in family functioning. After all, both kinds of outcomes are included in the lists of variables that showed and failed to show an association with marriage-parenting groups (after controlling for family background differences between groups). Just as significant is the fact that the very outcomes that proved insensitive to variation in patterns of marriage and parenting in this inquiry have proven to be related to variation in child-care experiences in other analyses carried out on this data set. Such results begin to suggest that marriageparenting patterns may uniquely influence some features of child development rather than others. Before entertaining possible explanations for such patterns of differential prediction, we judge it wise to wait for findings that replicate our own.

Protective buffering comparisons. Evidence of protective buffering emerged only with respect to the eight comparisons involving the Consistently Risky and the Good-Parenting/PoorMarriage groups. That is, no differences were detected between Consistently Risky and PoorParenting/Good-Marriage groups when child functioning was examined after controlling for family background factors. More specifically, recall that children growing up in households in which neither marriage nor parenting were (pre)judged to be developmental resources (i.e., Consistently Risky) received lower ratings by teachers on language skills and scored more poorly on the cognitive test battery than did children living in households in which only parenting was (pre)judged to be a developmental resource (i.e., Good-Parenting/PoorMarriage). Consistent with a developmental psychopathology perspective on risk and protective factors, such data clearly suggest that children's development is somewhat protected when a relatively poor marriage is compensated for by relatively sensitive mothering and fathering, at least relative to children growing up in households in which neither marriage 
nor parenting seem particularly supportive of development. Indeed, these compensatoryprocess comparisons highlight once again the relative power of parenting processes over and above marital ones in seeming to foster positive development, at least as measured in this inquiry. After all, no developmental differences were detected between the Continuously Risky and the Poor-Parenting/GoodMarriage group, and this was so irrespective of whether background differences between the two groups were taken into account. The failure of marital strengths to compensate for (relative) parenting limitations in this set of comparisons is consistent with evidence summarized earlier showing that the GoodParenting/Poor-Marriage group outperformed the Poor-Parenting/Good-Marriage group. That is, when the only source of (relative) family strength is the marital relationship, it neither protects the child from the developmental costs of growing up in a household with no apparent marital or parenting strengths (i.e., Consistently Risky) nor proves to be more strongly related to child well being than growing up in a household in which the only source of (relative) family strength involves parenting.

\section{Conclusion}

In exploring possible types of families using marital and parenting data collected for an entirely different purpose, we believe that we have identified what appear to be meaning-

\section{References}

Achenbach, T. M. (1991). Manual for the Teacher's Report Form and 1991 Profile. Burlington, VT: University of Vermont Department of Psychiatry.

Ahrons, C. (1981). The continuing coparental relationship between divorced spouses. American Journal of Orthopsychiatry, 51, 415-428.

Aldous, J. (1977). Family interaction patterns. Annual Review of Sociology, 3, 105-135.

Amato, P. (1986). Marital conflict, the parent-child relationship, and child self-esteem. Family Relations, 35, 403-410.

Anderson, A., Russell, C., \& Schumm, W. (1983). Perceived marital quality and family life cycle categories. Journal of Marriage and the Family, 45, 127-139.

Belsky, J. (1979). The interrelation of parental and spousal behavior during infancy in traditional nuclear families: An exploratory analysis. Journal of Marriage and the Family, 41, 62-68. fully different family systems which, at the very least, highlight what may be obscured in much research on marriage, parenting, and child development, which treats the first two domains of measurement in a standard, continuous manner when trying to examine their interrelation and potential effect upon child development. Indeed, the fact that in this inquiry marital and parenting quality appeared to be generally positively correlated across $75 \%$ of the sample but negatively correlated across the remaining $25 \%$ may account not only for why most investigations detect positive relations between measures of marriage and parenting but also for why some others detect negative relations. Conceiveably, the sampling of different types of families across studies could account not only for such differences, but explain why the marriageparenting linkage does not appear even in metaanalyses stronger than it does.

It must be appreciated in this attempt to work from a family-systems' perspective, that the emphasis has not been specifically placed on disentangling the independent effects of marriage and parenting, but on charting the antecedents and sequelae of what look to be very different types of families. Only future work adopting a similar, typological approach will determine the extent to which the types of families identified in our latent-class analysis (and their correlates) are specific to the sample under study. It is just such work that this investigation was designed to stimulate, as much as anything else.

Belsky, J. (1981). Early human experience: A family perspective. Developmental Psychology, 17, 3-23.

Belsky, J. (1984). The determinants of parenting: A process model. Child Development, 55, 83-96.

Belsky, J., Crnic, K., \& Gable, S. (1995). Determinants of coparenting in families with toddler boys: Spousal differences and daily hassles. Child Development, 66 , $629-642$.

Belsky, J., \& Fearon, R. M. P. (2002a). Early attachment security, subsequent maternal sensitivity, and later child development: Does continuity in development depend upon continuity of caregiving? Attachment and Human Development, 3, 361-387.

Belsky, J., \& Fearon, R. M. P. (2002b). Infant-mother attachment security, contextual risk and early development: A moderational analysis. Development and Psychopathology, 14, 293-310.

Belsky, J., \& Jaffee, S. (in press). The multiple determi- 
nants of parenting. In D. Cicchetti \& D. J. Cohen (Eds.), Handbook of psychopathology (2nd ed.). New York: Wiley.

Belsky, J., Putnam, S., \& Crnic, K. (1996). Coparenting, parenting and early emotional development. New Directions in Child Development, 74, 45-56.

Belsky, J., Rovine, M., \& Fish, M. (1989). The developing family system. In M. Gunnar \& E. Thelen (Eds.), Minnesota Symposia of Child Psychology: Vol. 22. Systems and development (pp. 119-166). Hillsdale, NJ: Erlbaum.

Belsky, J., Woodworth, S., \& Crnic, K. (1996a). Troubled family interaction during toddlerhood. Development and Psychopathology, 8, 477-495.

Belsky, J., Woodworth, S., \& Crnic, K. (1996b). Trouble in the second year: Three questions about family interaction. Child Development, 67, 556-578.

Belsky, J., Youngblade, L., Rovine, M., \& Volling, B. (1991). Patterns of marital change and parent-child interaction. Journal of Marriage and Family, 53, 487-498.

Birch, S., \& Ladd, G. (1997). The teacher-child relationship and children's early school adjustment. Journal of School Psychology, 35, 61-80.

Brody, G. H., Pillegrini, A. D., \& Sigel, I. E. (1986). Marital quality and mother-child and father-child interactions with school-aged children. Developmental Psychology, 22, 291-296.

Buchanan, C. M., \& Waizenhofer, R. (2001). The impact of interparental conflict on adolescent children. In A. Booth, A. Crouter, \& M. Clements (Eds.), Couples in conflict (pp. 149-160). Mahwah, NJ: Erlbaum.

Buehler, C., Anthony, C., Krishnakumar, A., Stone, G., Gerard, J., \& Pemberton, S. (1997). Interparental conflict and youth problem behaviors: A meta-analysis. Journal of Child and Family Studies, 6, 14-31.

Buehler, C., \& Gerard, J. (2002). Marital conflict, ineffective parenting, and children's and adolescents' adjustment. Journal of Marriage and the Family, 64, 78-92.

Burman, B., John, R., \& Margolin, G. (1987). Effects of marital and parent-child relations on children's adjustment. Journal of Family Psychology, 1, 91-108.

Burr, W. (1970). Satisfaction with various aspects of marriage over the life cycle. Journal of Marriage and the Family, 26, 29-37.

Cicchetti, D., \& Cohen, D. J. (1995). Perspectives on developmental psychopathololgy. In D. Cicchetti \& D. J. Cohen (Eds.), Developmental psychopathology (pp. 3-20). New York: Wiley.

Cowan, C. P., \& Cowan, P. A. (1992). When partners become parents: The big life change for couples. New York: Basic Books.

Cox, M. J., Owen, M. T., Lewis, J. M., \& Henderson, V. K. (1989). Marriage, adult adjustment, and early parenting. Child Development, 60, 1015-1024.

Cox, M. J., Paley, B., \& Harter, K. (2001). Interparental conflict and parent-child relationships. In J. Grych \& F. Fincham (Eds.), Interparental conflict and child development: Theory, research and applications ( $\mathrm{pp}$. 249-272). Cambridge: Cambridge University Press.

Cummings, E. M., \& Davies, P. (1994). Children and marital conflict: The impact of family dispute and resolution. New York: Guilford Press.

Cummings, E. M., \& Davies, P. (2002). Effects of marital conflict on children: Recent advances and emerging themes in process-oriented research. Journal of Child Psychology and Psychiatry, 43, 31-63.
Davies, P., \& Cummings, E. M. (1994). Marital conflict and child adjustment: An emotional security hypothesis. Psychological Bulletin, 116, 387-411.

Davies, P., \& Forman, E. (2002). Children's patterns of preserving emotional security in the interparental subsystem. Child Development, 73, 1880-1903.

Depner, C., Leino, E., \& Chun, A. (1991). Interparental conflict and child adjustment: A decade review and meta-analysis. Family and Conciliation Courts Review, 30, 323-341.

Dickie, J. (1987). Interrelationships within the motherfather-infant triad. In P. Berman \& F. Pedersen (Eds.), Men's transitions to parenthood (pp. 113-143). Hillsdale, NJ: Erlbaum.

Duvall, E. (1971). Family development (4th ed.). Philadelphia, PA: Lippincott.

Egeland, B., \& Heister, M. (1995). The long-term consequences of infant day care and mother-infant attachment. Child Development, 66, 474-485.

Emery, R. (1982). Interparental conflict and the children of discord and divorce. Psychological Bulletin, 92, 310-330.

Erel, O., \& Burman, B. (1995). Interrelatedness of marital relations and parent-child relations: A metaanalytic review. Psychological Bulletin, 118, 108-132.

Fauber, R., Forehand, R., Thomas, A. M., \& Wierson, M. (1990). A mediational model of the impact of marital conflict on adolescent adjustment in intact and divorce families: The role of disrupted parenting. Child Development, 61, 1112-1123.

Feldman, S., Nash, S., \& Aschenbrenner, B. (1983). Antecedents of fathering. Child Development, 54, 1628-1636.

Fincham, F. D., Grych, J. H., \& Osborne, L. N. (1994). Does marital conflict cause child maladjustment? Directions and challenges for longitudinal research. Journal of Family Psychology, 8, 128-140.

Floyd, F. J., Gilliom, L. A., \& Costigan, C. L. (1998). Marriage and the parenting alliance: Longitudinal prediction of change in parenting perceptions and behaviours. Child Development, 69, 1461-1479.

Goldberg, W. A., \& Easterbrooks, M. A. (1984). Role of marital quality in toddler development. Developmental Psychology, 20, 504-514.

Gresham, F., \& Elliott, S. (1990). The Social Skills Rating System. Circle Pines, MN: American Guidance Service.

Grossman, F., Pollack, W., \& Golding, E. (1988). Fathers and children: Predicting the quality and quantity of fathering. Developmental Psychology, 24, 82-91.

Grych, J. (2002). Marital relationships and parenting. In M. Bornstein (Ed.), Handbook of parenting: Social conditions and applied parenting (2nd ed., Vol. 4, pp. 203-225). Mahwah, NJ: Erlbaum.

Haley, J. (1976). Problem-solving therapy. San Francisco, CA: Jossey-Bass.

Hamre, B., \& Pianta, R. C. (2001). Early teacher-child relationships and the trajectory of children's school outcomes through eighth grade. Child Development, $72,625-638$.

Harold, G. T., \& Conger, R. D. (1997). Marital conflict and adolescent distress: The role of adolescent awareness. Child Development, 68, 333-350.

Harold, G. T., Fincham, F. D., Osborne, L. N., \& Conger, R. D. (1997). Mom and dad are at it again: Adolescent perceptions of marital conflict and adolescent psychological distress. Developmental Psychology, 33, 333-350. 
Hetherington, E., Bridges, M., \& Insabella, G. (1998). What matters? What does not?: Five perspectives on the association between marital transitions and children's adjustment. American Psychologist, 53, 167-184.

Howes, P., Cicchetti, D., \& Rogosch, F. (2000). Affective, organizational, and relational characteristics of maltreating families: A systems perspective. Journal of Family Psychology, 14, 95-110.

Johnson, V. (2003). Linking changes in whose family functioning and children's externalizing behaviour across the elementary school years. Journal of Family Psychology, 17, 499-509.

Jouriles, E., Murphy, C., Farris, A., Smith, D., Richters, J., \& Waters, E. (1991). Marital adjustment, parental disagreements about child rearing, and behavior problems in boys: Increasing the specificity of the marital assessment. Child Development, 62, 1424-1433.

Kerig, P. (1995). Triangles in the family circle: Effects of family structure on marriage, parenting, and child adjustment. Journal of Family Psychology, 9, 28-43.

Krishnakumar, A., \& Buehler, C. (2000). Interparental conflict and parenting behaviors: A meta-analytic review. Family Relations, 49, 25-44.

Lindahl, K., \& Malik, N. (1999). Observations of marital conflict and power: Relations with parenting in the triad. Journal of Marriage and the Family, 61, 320-330.

Mandara, J., \& Murray, C. (2002). Development of an empirical typology of African American family functioning. Journal of Family Psychology, 16, 318-337.

Marshall, N. L., \& Barnett, R. C. (1991). Race and class and multiple role strains and gains among women employed in the service sector. Women and Health, 17, 1-19.

McHale, J., Khazan, I., Erera, P., Rotman, T., DeCourcey, W., \& McConnell, M. (2002). Coparenting in diverse family systems. In M. Bornstein (Ed.), Handbook of parenting: Being and becoming a parent (2nd ed., Vol. 3, pp. 75-107). Mahwah, NJ: Erlbaum.

McHale, J., \& Rasmussen, J. (1998). Coparental and family group-level dynamics during infancy: Early family precursors of child and family functioning during the preschool. Development and Psychopathology, 10, 39-58.

McHale, J. P. (1995). Coparenting and triadic interactions during infancy: The roles of marital distress and child gender. Developmental Psychology, 31, 985-996.

Meins, E. (1997). Security of attachment and the social development of cognition. London: Psychology Press.

Minuchin, S. (1974). Families and family therapy. Cambridge, MA: Harvard University Press.

NICHD Early Child Care Research Network. (1999). Child care and mother-child interaction in the first three years of life. Developmental Psychology, 35, 13991413.

NICHD Early Child Care Research Network. (2000). Factors associated with fathers' caregiving activities and sensitivity with young children. Journal of Family Psychology, 14, 200-219.

NICHD Early Child Care Research Network. (2003). Early child care and mother-child interaction from 36 months through first grade. Infant Behavior and Development, $26,345-370$.

O’Connor, T., Hetherington, E. M., \& Reiss, D. (1998). Family systems and adolescent development. Development and Psychopathology, 10, 353-375.

Osborne, L. N., \& Fincham, F. D. (1996). Marital conflict, parent-child relationships, and child adjustment: Does gender matter? Merrill-Palmer Quarterly, 42, 48-75.

Pedersen, F. A., Anderson, B. J., \& Cain, R. L. J. (1980). Parent-infant and husband-wife interactions observed at age five months. In F. A. Pedersen (Ed.), The fatherinfant relationship (pp. 71-96). New York: Praeger.

Pianta, R. C. (2001). Student-Teacher Relationship Scale. Odessa, FL: PAR, Inc.

Radloff, L. S. (1977). The CES-D Scale: A self-report depression scale for research in the general population. Applied Psychological Measurement, 1, 385-401.

Reid, W., \& Crisafulli, A. (1990). Marital discord and child behavior problems: A meta-analysis. Journal of Abnormal child Psychology, 18, 105-117.

Schaefer, E., \& Edgarton, M. (1985). Parental and child correlates of parental modernity. In I. Sigel (Ed.), Parental belief systems: The psychological consequences for children (pp. 287-318). Hillsdale, NJ: Erlbaum.

Schaefer, M., \& Olson, D. (1981). Assessing intimacy: The Pair Inventory. Journal of Marital and Family Therapy, 7, 640-653.

Sroufe, L. A. (1988). The role of infant-caregiver attachment in development. In J. Belsky \& T. Nezworski (Eds.), Clinical implications of attachment (pp. 18-40). Hillsdale, NJ: Erlbaum.

Stoneman, Z., Brody, G., \& Burke, M. (1989). Marital quality, depression, and inconsistent parenting: Relationship with observed mother-child conflict. American Journal of Orthopsychiatry, 59, 105-117.

Stright, A., \& Neitzel, C. (2003). Beyond parenting: Coparenting and children's classroom adjustment. International Journal of Behavioral Development, 27, 31-40.

US Department of Labor, Bureau of Labor Statistics. (1994). Current population survey, March 1992, as cited in US Department of Labor, Women's Bureau (1993). Handbook on women workers: Trends and issues. Washington, DC: US Government Printing Office.

Vandell, D. L. (1979). Effects of a playgroup experience on mother-son and father-son interaction. Developmental Psychology, 15, 379-385.

Van Ijzendoorn, M., Dijkstra, J., \& Bus, A. (1995). Attachment, intelligence, and language: A meta-analysis. Social Development, 4, 115-128.

Vermunt, J., \& Magidson, J. (2000). Latent gold 2.0 user's guide. Belmont, MA: Statistical Innovations Inc.

Walsh, F. (1993). Normal family processes. New York: Guilford Press.

Winer, B. J. (1971). Statistical principles in experimental design (2nd ed.). New York: McGraw-Hill.

Woodcock, R. W., \& Johnson, M. B. (1989). WoodcockJohnson Psycho-Educational Battery-Revised. Allen, TX: DLM. 